\title{
CORRIGENDUM
}

\section{STRUCTURAL BIOLOGY: HDAC6 finally crystal clear}

Yanli Liu, Li Li \& Jinrong Min

Nat. Chem. Biol. 12, 660-661 (2016); published online 18 August 2016; corrected after print 26 August 2016.

In the article originally published, the author omitted a reference describing the discovery of HDAC6. This reference is now included as reference 9. The error has been corrected in the HTML and PDF versions of the article. 